\title{
Selective medical examinations for school entrants: the way forward
}

\author{
S Richman, M Miles
}

Routine medical inspections have been a traditional part of starting school in the United Kingdom since the early 1900 s. When the school health services were incorporated into the NHS in 1974 medical inspections ceased to be a statutory requirement, and the numbers of routine medical examinations of children over the age of 5 have declined. Most areas have, however, retained a system of routine medical examinations for all children when they start primary school, sometimes including a thorough neurodevelopmental assessment as well as a physical examination. ${ }^{12}$

The value of this system was questioned by the Court Committee on Child Health Services, ${ }^{3}$ and in later reports. ${ }^{4}$ Retrospective analyses of school entry medical examinations have not shown routine examination of all children to be particularly advantageous ${ }^{6-9}$ and, increasingly, the value of such routine examinations is being challenged. ${ }^{9} 10$ Systems of selective medical examination at the time of entry to primary school are already successfully in operation in some parts of Britain and Australia. ${ }^{11-13}$

This paper describes the organisation of selective school entrance medical examinations in a socially deprived inner city district of London with a mobile population, and presents the results of the initial pilot study that assessed the feasibility of such a system.

\section{Background}

The former health district of Paddington and North Kensington constitutes a deprived inner city area of London, with widespread unemployment and a large proportion of recent immigrants especially from Morocco and Bangladesh. Services for preschool children are based at local child health clinics, and include immunisation and developmental screening. The latter is performed by community child health doctors at 6 weeks, and by health visitors at 15 months and 3 years. When a child starts school at the age of 5 years, the community child health record is transferred from the health visitor to the appropriate school nurse, either directly or through the centralised school health department. Before the start of the selective medical system, every child was seen by both the school nurse (for testing of hearing and vision and measurement of height and weight, and completion of a health questionnaire with the parent) and the school doctor (for detailed medical and neurodevelopmental examination) after one term in school.

\section{Selection for medical examinations}

A system has been introduced whereby the subgroup of children who actually need a medical examination is identified and the remaining children are seen by the school nurse for a health interview. The selection is carried out jointly by the school nurse and doctor, who review the preschool records and have discussions with parents and teachers.

At the end of each term, children who have started school that term are reviewed. The preschool community health records are studied, particular attention being paid to concerns expressed at the child's 3 year check. The immunisation record is noted, and whether a record has been made of testicular descent and auscultation of the heart. A meeting is held with the reception class teachers at which they are invited to voice any concerns they have about that term's entrants. The meeting is also used as an information sharing exercise, enabling the teachers' concerns to be discussed in the light of the child's health records, and allowing information to be passed to the teachers about any major health problems of which they have been unaware.

As a result of this review process, a number of children can be identified as needing a medical examination. Children with chronic health problems, those previously identified as having possible special educational needs (for example, defects of vision or hearing, or developmental delay), and those with a history of child abuse or severe emotional or social deprivation, come into this category, as do children about whom the teachers are worried. Not all such children automatically see the doctor, however. The particular problem is discussed by the doctor and nurse; occasionally more information has to be obtained, such as hospital letters. A medical examination is then arranged if the problem seems to need a doctor to clarify matters or to intervene. In some cases-for example, a child with asthma who is not having difficulties at school-a medical examination is not considered appropriate.

Initially a medical examination was also arranged if preschool records were not available or if a child had no record of a 3 year review and had not been seen subsequently by a doctor or 
health visitor. This system was modified after one term of the pilot study to exclude children who were presumed to have had preschool health care but whose records had not yet been received by the school nurse; children new to the United Kingdom are still seen by the school doctor.

The remaining children are all seen (with a parent) by the school nurse for a health interview. The existing questionnaire is used to obtain details of past medical and developmental history, present symptoms, and immunisations; this is either sent to the home for the parent to complete before the health interview or completed by the school nurse and the parent together. Parents are asked directly about any concerns they may have about their child, and are asked whether they wish to see the school doctor. The child's height and weight are recorded and hearing and vision are tested.

The health interviews and selected medical examinations take place in the child's second term at school. Those having medical examinations have their growth, hearing, and vision checked by the school nurse in the usual way, and the same questionnaire is used as for the health interview. A few children are offered a medical examination after their health interviews, either at the parent's request or if the school nurse identifies a problem that cannot be dealt with simply by discussion with the school doctor. If immunisations are incomplete parents are invited to bring the child to the next immunisation session at the local child health clinic.

\section{Administration and follow up}

Details are recorded of the number of health interviews and medical examinations carried out, the problems that have been identified, and the action to be taken. At the end of each term a review is made by the school doctor and nurse of the term's medical examinations and health interviews. This is to keep track of nonattenders, and a check that all planned interviews and medical examinations have taken place. A check is also made of outstanding immunisations to ensure that the child has been taken to the clinic if necessary.
Subsequent review and monitoring of problems or defects can mostly be carried out by the school nurse, who will have received appropriate training. These include the management of enuresis, or monitoring of minor abnormalities of vision.

\section{Results of pilot study}

Two schools in North Kensington were included in the pilot study, both representative of the district as a whole. A total of 52 children aged 5 started school during the year being studied. Initially $14(27 \%)$ were selected to have medical examinations; the rest saw the school nurse for a health interview. After the health interview, a further three children $(6 \%)$ saw the doctor. The reasons for the medical examinations and their outcomes are shown in table 1 . The most common reason for an examination (accounting for $35 \%$ of the total) was the absence of preschool records. The only problems identified in these children were one hearing deficit and one minor defect of visual acuity; in both cases the problem was identified by the school nurse on screening. Four children $(24 \%)$ were seen because they were on the Child Protection Register; for all these follow up by the school nurse was felt to be appropriate. Two (12\%) were seen because of teachers' concerns and two at the parents' request.

\section{Health problems identified}

The main problems identified at both the health interviews and the medical examinations are shown in table 2 . Altogether, 20 children (38\%) had a total of 24 health problems. Five of these problems were already known to the community child health services; a further two were receiving treatment but were not recorded in the community notes. Another four children's parents $(8 \%)$ were worried about their children's health; two of these children subsequently saw the doctor and all were reassured with no further action being required. Defects of hearing and vision were the most common, accounting for a total of 11 of 18 problems $(61 \%)$. None of these defects had been pre-

Table 1 Details of selective medical examinations

\begin{tabular}{|c|c|c|c|}
\hline Reason for medical examination & No $(\%)$ & Findings & Action/follow up \\
\hline \multicolumn{4}{|l|}{ Initially: } \\
\hline $\begin{array}{l}\text { New immigrants } \\
\text { Missing records }\end{array}$ & $3(18)$ & $\begin{array}{l}\text { Hearing loss }(n=1) \\
\text { Visual acuity deficit }(n=1) \\
\text { Healthy }(n=1)\end{array}$ & $\begin{array}{l}\text { None } \\
\text { Referred for audiological assessment } \\
\text { School nurse to follow up } \\
\text { None }\end{array}$ \\
\hline History of congenital dislocation of hips & $1(6)$ & No disability & None \\
\hline Asthma: for evaluation & $1(6)$ & Well controlled & None \\
\hline On Child Protection Register & $4(24)$ & All healthy & School nurse to follow up \\
\hline \multicolumn{4}{|l|}{ Teacher concerned: } \\
\hline $\begin{array}{l}\text { Abdominal pains } \\
\text { Developmental delay }\end{array}$ & $1(6)$ & Resolved before medical & None \\
\hline \multirow{2}{*}{\multicolumn{4}{|c|}{ After health interview: }} \\
\hline & & & \\
\hline $\begin{array}{l}\text { Sleeping problem } \\
\text { 'Blocked nose' }\end{array}$ & $1(6)$ & Emotional upset & School doctor to follow up \\
\hline \multicolumn{4}{|l|}{ School nurse request: } \\
\hline Hearing problem & $1(6)$ & Mild hearing loss & School nurse to follow up \\
\hline Total & $17(100)$ & & $\begin{array}{l}(n=2) \text { Specialist referral } \\
(n=3) \text { School nurse to follow up } \\
(n=1) \text { School doctor follow up }\end{array}$ \\
\hline
\end{tabular}


Table 2 Details of all health problems identified

\begin{tabular}{|c|c|c|c|c|}
\hline Problem & Newly indentified & $\begin{array}{l}\text { Not known to } \\
\text { community health services } \\
\text { but receiving treatment }\end{array}$ & $\begin{array}{l}\text { Known to } \\
\text { community health services }\end{array}$ & Total \\
\hline $\begin{array}{l}\text { Hearing } \\
\text { Vision } \\
\text { Speech } \\
\text { Enuresis } \\
\text { Urinary tract infections } \\
\text { Asthma } \\
\text { Sleeping problems } \\
\text { Developmental delay } \\
\text { Adverse social circumstances }\end{array}$ & $\begin{array}{l}7 \\
6 \\
0 \\
2 \\
0 \\
0 \\
1 \\
1 \\
0\end{array}$ & $\begin{array}{l}0 \\
0 \\
1 \\
0 \\
1 \\
0 \\
0 \\
0 \\
0\end{array}$ & $\begin{array}{l}0 \\
0 \\
0 \\
0 \\
0 \\
1 \\
0 \\
0 \\
4\end{array}$ & $\begin{array}{l}7 \\
6 \\
1 \\
2 \\
1 \\
1 \\
1 \\
1 \\
4\end{array}$ \\
\hline Total & 17 & 2 & 5 & 24 \\
\hline
\end{tabular}

viously recognised; two of the children (representing three problems) needed referral for specialist assessment. We were encouraged by the fact that our rate of detecting problems was similar to that in districts in which all 5 year olds are routinely examined; the problems were also similar. 914 This suggests that the selection criteria are adequate and that it is not necessary for a child to see a doctor for relevant health problems to be detected.

\section{Non-attenders}

We decided that if parents did not attend for health interview a home visit would be made by the school nurse to complete the questionnaire and to obtain consent to test the child's hearing and vision at school. Eleven of the 52 children had not attended for health interviews by the end of the school year but were successfully seen at the beginning of the next term and no home visits were necessary. The secretary of one school was, however, invaluable in reminding persistent non-attenders of their appointments, and home visits might well have been needed without this help. Non-attenders for immunisation were reminded once by the school nurse; as a last resort immunisations could be undertaken by the doctor or nurse at school, and three children from this cohort were eventually immunised at school.

\section{Audit}

To check that the selective medical examination system identified problems correctly, all children will be reviewed at the age of 7 , by means of a questionnaire (already in use for the junior school reviews), which will be completed by the parents.

Problems in implementing the new system Problems were experienced in three main areas. The first, and most troublesome, was that of missing preschool records. We had anticipated this as North Kensington has a rapid turnover of children from mobile families with a high incidence of health problems and we initially questioned whether selection would be worth the extra administrative effort if most children would need to be seen to confirm that all was well. In practice, although problems were encountered in obtaining the preschool records, these did not upset the system. It was not only the mobile families who had this problem: several children known to have attended one of the two local child health clinics for 3 year checks and preschool booster immunisations were without records on school entry. This resulted in excessive administrative work for the nurses in trying to obtain records before deciding whether the child needed a medical examination, and in arranging unnecessary medical examinations.

Our eventual policy of offering routine medicals only to those children who definitely did not have records (predominantly new immigrants) was validated by the results: parents could usually confirm that their child had received preschool surveillance, and could supply the relevant information. Missing records and mobile families are a feature of inner London districts; a need for improved transfer of information has been suggested. ${ }^{14}$ Records held by parents would help and we hope that improved liaison between the school health teams and general practitioners will soon obviate the need for medical examinations for which the only indication is ausculation of a child's heart or confirmation that the testes have descended.

The second problem was the reservations that the educational staff had about the new system. These were encountered in both schools, but for different reasons. One head teacher felt that the responsibility for identifying children with problems was being shifted too heavily on to the teachers, and was unhappy about spending time meeting with the school nurse and doctor each term; this meeting was, however, preferred to our alternative suggestion of a questionnaire being completed by the teachers for each child. By the end of the pilot year, these worries seemed to have abated and the system was working well. In the other school, the problem was the opposite: a head teacher who had always worked closely with the school health team found it hard to accept that some worries that she raised could be dealt with competently by the school nurse without the need for a full medical examination. This, too, was only a temporary problem.

Finally, the school nurses found their changed role, with more responsibility for advising parents directly, somewhat daunting at first. The solution was to encourage regular discussions between the school nurse and doctor, which allowed joint decisions to be made and provided the necessary support for the nurse. 
By the end of the pilot year the nurses were enthusiastic about the selective system and found their new role more effective and more satisfying than in the past.

\section{Discussion}

At school entry the school health team aims to ensure that there are no unrecognised health problems that may restrict a child's ability to benefit from education. Most problems identified concerned vision and hearing, ${ }^{914}$ both of which are best detected by screening. ${ }^{5}$ Physical conditions may account for about $20 \%$ of recorded problems ${ }^{9}$; educationally relevant conditions are unlikely to be detected by physical examination alone in the absence of a history of chronic illness or past developmental, behavioural, or psychosocial problems. ${ }^{13}$ The proponents of routine school entry medical examinations for all children are largely concerned about detecting 'clumsy' children or those with possible learning difficulties. ${ }^{1} 215$ There is no doubt that existing detailed neurodevelopmental screening examinations are predictive of later problems if they are appreciably abnormal, ${ }^{2}{ }^{16}$ although they have been criticised for (among other things) lack of standardisation. ${ }^{17}$ The management of these problems, however, requires a multidisciplinary approach and it can be argued that the classroom is a more appropriate place to identify children who are underfunctioning. If necessary, health service time might be better used to increase teachers' awareness of predictive signs. In our pilot study the only child with a previously unrecognised neurodevelopmental problem was identified by the class teacher.

Another argument in favour of routine medical examinations is that not all children have access to preschool health care. ${ }^{1}$ The areas in which selective medical examinations are already used are mostly rural with good uptake of preschool surveillance, ${ }^{12}{ }^{13}$ but at least one inner city system has been reported, ${ }^{11}$ and our results show that even in a severely underprivileged area a policy of selective medical examinations can work well. Inadequate preschool surveillance should not be replaced by extra screening at school but by improving preschool services, now recognised as the most important aspect of child health surveillance. ${ }^{35}$

It has been said that parents like school medical examinations. ${ }^{18}$ No parents in our pilot study objected to the selective system and many were appreciative of their increased opportunity to discuss worries with the school nurse. Only two of the 38 parents seen (5\%) asked for medical examinations, both for valid reasons. We have deliberately opted for a system of health interviews with personal contact between parent and school nurse, rather than a postal questionnaire with screening of growth, hearing, and vision in the absence of the parent. This seems to have contributed to the parents' acceptability of the system. In line with current trends some responsibility was placed on the parents to express their worries and to request to see the school doctor. The traditional school health system leaves many parents confused and uncertain about the way it operates, ${ }^{19}$ and to be effective, the school health team of the future will need to provide advice for parents about the selective medical system and how to use it. If parents are to be able to play their full part it will be especially important for them to know the names of the school doctor and nurse and how they can be contacted and to be kept informed of the outcome of surveillance that their children receive.

The many positive aspects of selective medical examinations have been emphasised by our study. The role of the school nurse has been redefined, emphasising her position as the key person in the school health team. The school doctor can then be used more appropriately to provide secondary care. This leads to increased job satisfaction for both nurse and doctor. Children with disabilities, those with emotional problems, and those from deprived backgrounds, benefit the most from school health service time, but this is not always available and it has been pointed out that the redistribution of resources resulting from a system of selective medical examinations should lead to more medical time being available for those who really need it. ${ }^{10}$ We found that a problem could be dealt with thoroughly in a relatively long initial consultation, sometimes avoiding the necessity for repeat attendances or for referral elsewhere.

It now seems that there is no longer a place for routine medical examinations for all children at school entry. A health interview with the school nurse maintains the direct contact that parents prefer and allows efficient screening. Those children who do have problems benefit from the extra medical time available to them. There is an increased opportunity for health education by the school nurse. Some of the medical time freed may be profitably used in developing training programmes to increase the awareness of teachers of common health problems in school age children, which is less than optimal both for neurodevelopmental problems $^{15}$ and conditions such as asthma. ${ }^{20}$

Child health surveillance is currently the subject of much interest, and attempts are being made to rationalise the services provided. The emphasis for the future is on increasing parental concern with and responsibility for their children's health, ${ }^{5}$ with a reduction in less productive routine screening procedures. Selective school medical examinations, which are an important part of this new approach, can be successfully introduced in even a severely disadvantaged area with clear benefits to all.

We thank Mrs B Phellas and Mrs R Peltier for piloting the health interviews, Miss S Nason for help with data analysis, and Miss J Rifai for typing the manuscript.

1 Whitmore $K$, Bax $M$. The school entry medical examination. Arch Dis Child 1986;61:807-17.

2 Haines CR, Brown JB, Grantham EB, Rajagopalan VS Sutcliffe PV. Neurodevelopmental screen in the school entrant medical examination as a predictor of coordination entrant medical examination as a predictor of coordination and con 1122 .

3 Committee on Child Health Services. Fit for the future. London: HMSO, 1976. (Court report.)

4 British Paediatric Association. The school health services. London: British Paediatric Association, 1987.

5 Hall DMB, ed. Health for all children. A programme for child health surveillance. The Report of the Joint Working Party on Child Health Surveillance. Oxford: Oxford University Press, 1989. 
6 Whitmore K. The past, present and future of the health services for children in school. In: Macfarlane JA, ed. Progress in child health. Vol 1. London: Churchill Livingstone, 1984:213-29.

7 Oberklaid F. The ritual school health examination: an idea whose time has passed? Aust Paediatr $\mathcal{F}$ 1985;21:155-7.

8 Polnay L, Hull D. Community paediatrics. London: Churchill Livingstone, 1985:184.

9 Kennedy FD. Have school entry medicals had their day? Arch Dis Child 1988;63:1261-3.

10 Resznik R, Starte D, Morey S. Health screening at school entry - what is achieved? Aust Paediatr F 1985;21:159-62.

11 Turner S. Riverside child health project. Evaluation report. Newcastle: University of Newcastle upon Tyne, 1983.

12 O'Callaghan EM, Colver AF. Selective medical examinations on starting school. Arch Dis Child 1987;62:1041-3.

13 Oberklaid F. Selective examinations on starting school. Arch Dis Child 1988;63:225.

14 Rona RJ, Allsopp M, Morris R, Morgan M. Referral patterns after school medical examinations. Arch Dis Child 1989;64: 829-33.

15 Leach DJ. Screening for school learning difficulties. Occasional papers of the British Psychological Society; division of educational and child psychology. Vol 5 part 2. London British Psychological Society, 1981:46-59.

16 Bax $M$, Whitmore $K$. The medical examination of children on entry to school. The results and use of neurodevelop mental assessment. Dev Med Child Neurol 1987;29:40-55.

17 Henderson SE. The assessment of 'clumsy' children; old and new approaches. F Child Psychol Psychiatry 1987;28: 511-28.

18 Lucas S. Some aspects of child health care: contacts between children, general practitioners and school doctors. Community Med 1980;2:209-18.

19 Perkins ER. The school health service through parents' eyes. Arch Dis Child 1989;64:1088-91.

20 Hill RA, Britton JR, Tattersfield AE. Management of asthma in schools. Arch Dis Child 1987;62:414-5.

\section{Circumcision again}

The fate of the foreskin has not been to the fore as a topic of paediatric conversation in Britain since Douglas Gairdner wrote his memorable paper. ${ }^{1}$ Nevertheless, the pros and cons of routine circumcision of newborn babies are keenly debated in the United States and the New England fournal of Medicine recently published two opposing views. ${ }^{2}{ }^{3}$

Among arguments in favour of neonatal circumcision are the avoidance of balanoposthitis and phimosis and an apparent decrease in the incidence of infantile urinary infection and of later cancer of the penis in circumcised males and of cervical cancer in their sexual partners. Dr Schoen believes that the benefits of circumcision far exceed the risks but Dr Poland casts doubt on the methodology of the studies on urinary infection and recommends avoidance of human papilloma virus infection by reducing the number of sexual contacts and by appropriate use of condoms as more effective ways of preventing penile and cervical cancers. $\mathrm{He}$ concludes that the benefits of routine circumcision are uncertain and the decision should be left to the parents.

My guess is that British paediatricians will await further evidence before recommending routine operation for normal newborns. As for myself, I'm prejudiced. The possibility that such a primitive ritual could have any scientific justification is one I find difficult to swallow. How did nature, God, evolution, whatever you want to call it, get it wrong? Or did it?

\section{ARCHIVIST}

1 Gairdner D. The fate of the foreskin; a study of circumcision. $\mathrm{Br}$ Med $\mathcal{F} 1949$;ii: 1433-7.

2 Schoen EJ. The status of circumcision of newborns. N Engl f Med 1990;322:1308-12.

3 Poland RL. The question of routine neonatal circumcision. N Engl f Med 1990;322. 1312-5. 